\title{
LAS TRANSFORMACIONES DEL EMPLEO PÚBLICO COSTARRICENSE
}

\section{THE COSTARICAN PUBLIC JOB'S TRANSFORMATION}

\author{
Mario A. Ramírez Granados*
}

RESUMEN

El presente trabajo describe la figura del empleo público dentro del modelo estatal, su ubicación dentro de la evolución del Estado durante el Siglo XX y su aplicación y transformaciones en el Derecho Costarricense contemporáneo.

PALABRAS CLAVE: COSTA RICA * EMPLEO * AJUSTE ESTRUCTURAL * DERECHO ADMINISTRATIVO $*$ GOBIERNO $*$ FLEXIBILIDAD LABORAL

\section{ABSTRACT}

This work describes the treatment of "public employment" within the state model, its location in the State evolution during the XX century and its application and transformations in the modern Costa Rican Law.

KEY WORDS: COSTA RICA * EMPLOYMENT * STRUCTURAL ADJUSTMENT * ADMNISTRATIVE LAW $*$ GOVERMENT $*$ LABOR FLEXIBILITY

\section{SUMARIO}

Aspectos introductorios: El empleo público como reflejo de la concepción del Estado Generalidades sobre el surgimiento del empleo público El desarrollo del Empleo Público en la legislación costarricense La crisis de 1973 y sus repercusiones en la organización del empleo público Las repercusiones del modelo neoliberal en el empleo público costarricense El activismo judicial como freno a la discrecionalidad administrativa Algunos retos pendientes Conclusiones

Cursando la Maestría Centroamericana de Sociología de la Facultad de Ciencias Sociales de la Universidad de Costa Rica. maragra77@yahoo.com 
ASPECTOS INTRODUCTORIOS:

EL EMPLEO PÚBLICO COMO REFLEJO

DE LA CONCEPCIÓN DEL ESTADO

A la par del esquema del derecho administrativo, que define la actividad de la administración en servicios públicos y actos administrativos en sentido estricto, existe la regulación de la organización de la relación entre el Estado y sus servidores, como un régimen distinto del derecho al trabajo, mediante el concepto de empleo público.

Tradicionalmente el tratamiento del empleo público en la doctrina (Vargas y Robert, 1990; Romero, 1999; Bautista, 2007; Hines, 2008) se ha centrado en el estudio de la legislación estatutaria, la cual es vista como una institución trasplantada (López) de la legislación francesa.

Con la excepción de Romero (1999) el enfoque predominante no permite dar cuenta de las transformaciones del empleo público en particular de la proliferación del trabajo interino en la coyuntura actual. Se propone entonces que el régimen de empleo en propiedad y del empleo interino debe ser entendido a la luz de una teoría más amplia, que integre esta visión con el devenir del Estado. En la primera parte se abordará en forma somera el surgimiento del empleo público como institución en los Estados europeos del siglo XIX, como un honor social, referido directamente al proyecto de consolidación del Estado. En un segundo punto, se analiza su surgimiento en consolidación en Costa Rica dentro del modelo de Estado de Bienestar. Una tercera sección se ocupa de las trasformaciones del empleo público como institución del Derecho Administrativo en el paradigma neoliberal. Un cuarto punto se ocupa de la implementación de la ideología neoliberal en Costa Rica. Un quinto punto se centra en el papel de la Sala Constitucional en la protección de los derechos de los funcionarios públicos. Finalmente, se apuntan algunas líneas sobre retos pendientes en el ámbito del empleo público.

GENERALIDADES SOBRE EL SURGIMIENTO DEL EMPLEO PÚBLICO

La doctrina nacional toma como punto de partida del Derecho Estatutario, el surgimiento del Estado napoleónico en Francia. Si bien el modelo francés es muy influyente, el enfoque moderno de empleo público surge en Europa durante el siglo XIX, a partir de diferentes influencias como "el impacto de la burocracia prusiana en los escritores decimonónicos, la creación de funcionarios profesionales en Inglaterra, el descontento producido por el tráfico constante de influencias en la Administración estadounidense $e^{1}$ y el desarrollo de la teoría weberiana sobre la democracia (Cf. Vile, 2007: 6).

Dentro de estos Estados surge la necesidad de la creación de nuevos puestos que van a reemplazar a la nobleza y el clero, los cuales se definen como estamento civil en el contexto de la unificación y consolidación de los Estados. Desde esta concepción, el empleado público deja de ser un servidor personal de la Corona para convertirse en funcionario del Estado, ente personal regido por leyes (Sánchez, 2002: 38).

De acuerdo con Romero, el empleo público es una posición social, nombrada por una autoridad superior y con cierta perpetuidad en el cargo, que recibe una remuneración en forma de estipendio fijo, que se fija de acuerdo con las funciones, el rango y duración en el tiempo de servicios, esto es lo que se denomina anualidades (Cf. Romero, 1999: 342-343. En el mismo sentido Weber, 1999: 176).

Parte de la doctrina española reconoce esta interpretación del empleo público como posición social señalando que este debe ser entendido no sólo desde un aspecto de relación laboral entre el servidor y el Estado, sino como un sistema de progresión económica y social, que concibe a la relación de empleo público como una especie de causus honorum y un instrumento de jerarquización administrativa (Cf. Sánchez, 2002:151).

Dentro de esta idea originaria del empleo público, surge la idea de la diferenciación de la relación laboral con respecto a este. La relación jurídica del funcionario público con el Estado no se encuentra regida por un contrato de trabajo o un convenio colectivo sino a través

1 A este tipo de organización, es lo que la doctrina especializada, entre ellos Sánchez Morón siguiendo a Weber denomina Spoil sistem. 
de una regulación propia que define los mecanismos de ingreso del servidor al régimen de empleo, sus derechos, sus deberes y los modos de terminación de la relación, al que se denomina estatutaria.

Este proceso de creación del empleo público se ve acompañado de la expansión de las tareas del Estado, más allá de las labores de vigilancia o fomento y creación de infraestructura hacia la creación de servicios sociales durante el período de la Posguerra como la gestión de la salud, la educación y la satisfacción de necesidades como el suministro de agua potable, electricidad, tratamiento de aguas negras, entre otras; o la intervención de la economía.

Esta expansión estatal es el correlato de las ideas de la Posguerra, sobre todo el keynesianismo, que entiende que el capitalismo de libre mercado no garantiza el equilibrio de pleno empleo, por lo que el Estado debe intervenir en las economías con el fin de disminuir el desempleo involuntario y aumentar la producción. Esta participación en la economía, la organización del sector financiero, la creación $y$ fortalecimiento del mercado laboral mediante la legislación social (salarios mínimos, jornadas fijas $y$ derecho a la seguridad social) $y$ la constitución de espacios bipartitos y tripartitos de negociación (Cf. Villareal, 1986; Harvey, 2004).

\section{EL DESARROLLO DEL EMPLEO PÚBLICO EN LA LEGISLACIÓN COSTARRICENSE}

En Costa Rica el surgimiento del empleo público se encuentra directamente relacionado con la concepción del Estado. Así durante el Estado Liberal, los servicios públicos eran muy limitados y el nombramiento de los servidores públicos se manejaba bajo el sistema de spoil sistem.

En el caso costarricense, el concepto de empleo moderno surge a través y en conjunto con el Estado de Bienestar derivado de la Guerra Civil de 1948. Constitucionalmente está en los artículos 191 y 192 de la Constitución Política y fue desarrollada posteriormente con la promulgación del Estatuto del Servicio Civil.

Dicho modelo propicia el desarrollo de una industria orientada al consumo nacional $y$ regional, en detrimento de los grandes agroexportadores, lo cual va a fomentar el desarrollo de nuevos empleos en la zona urbana, que se concentran principalmente en el sector servicios, desde donde el Estado va a cumplir una importante labor como empleador.

De acuerdo con Rodríguez, el Estado se convirtió no sólo en el principal empleador sino también en el sector más dinámico y moderno. Dentro de sus logros destaca la incorporación de las mujeres en trabajos no manuales como educación y salud (Cf. 2007: 84).

La concepción de empleo público desarrollada en los primeros años del Estado de Bienestar responde a un proyecto de Estado fuerte que se constituye a partir de la expropiación de monopolios privados (como la electricidad), la incursión en áreas no desarrolladas por la empresa privada (como la construcción de obra pública).

Sin embargo, la progresiva incidencia del Estado en diferentes áreas de la vida social mediante las instituciones autónomas, ha obligado a crear algunos cuerpos jurídicos, lo cual ha llevado a que exista una proliferación de normas de empleo público.

El Estatuto del Servicio Civil indica que la entrada del aspirante al régimen estatutario se realiza mediante pruebas de idoneidad, las cuales serán responsabilidad de un ente especializado al que se denomina la Dirección General del Servicio Civil.

Desde esta concepción, la existencia del trabajo interino es una norma planteada en el Estatuto del Servicio Civil con el propósito de llenar la ausencia temporal de funcionarios propietarios o resolver una necesidad de servicio público, mientras se creaba la plaza. Nótese que en el caso de la educación, permite incluso la posibilidad de nombrar personal no calificado, con el fin de garantizar la progresiva apertura de colegios en zonas alejadas e ir introduciendo progresivamente la profesionalización del sector docente. En ese sentido indica el artículo 97:

\section{Artículo 97}

A falta de personal calificado para servir plazas en instituciones educativas de cualquier tipo, podrán ser 
designados para ocuparlas, candidatos que, sin reunir la totalidad de los requisitos, se hayan sometido a pruebas de aptitud o concursos de antecedentes, que permitan seleccionar el candidato de mayor idoneidad, a juicio del Departamento de Personal del Ministerio de Educación Pública, quien cuenta para ello, con los servicios de los asesores supervisores correspondientes. Estos servidores ocuparán los cargos en calidad de "autorizados" o "aspirantes" y permanecerán en sus puestos mientras no haya personal calificado. Quedan a salvo los casos en el artículo siguiente Las relaciones de los educadores que ocupen puestos "interinos", se regirán por las disposiciones reglamentarias pertinentes, sobre contratos o (sic) plazo fijo.

\section{Artículo 98}

El Ministerio de Educación Pública, la Universidad de Costa Rica o ambas instituciones en programas cooperativos, ofrecerán a los "interesados" (sic) y "aspirantes" bachilleres, que sirvan en enseñanza primaria, en lugares incómodos o insalubres, oportunidades para alcanzar la condición profesional exigida para este nivel.

En tanto sigan regularmente con éxito los cursos a que se refiere el artículo anterior, $y$ hayan obtenido calificación de servicios, estos servidores gozarán de estabilidad en sus cargos. Podrán luego, cuando las condiciones lo permitan, concursar para puestos en propiedad.

Por su parte, el Reglamento del Estatuto del Servicio Civil define dos tipos de trabajador interino:

\section{Artículo 10}

Se considera un trabajador interino sustituto los que fueron nombrados para reemplazar temporalmente a un servidor regular por cualquier causa de suspensión del servicio.

\section{Artículo 12}

Cuando no haya en la Dirección General candidatos elegibles y sea necesario efectuar para llenar plazas vacantes, se podrán hacer nombramientos interinos, previa presentación del pedimento de personal correspondiente, $y$ si ello se estimare indispensable, durante el tiempo que requiera la Dirección General para la integración de la nómina de legibles.

En ese sentido como indica Bautista, el interinazgo es una condición de carácter temporal, que tiene por objeto garantizar la continuidad de los servicios que presta el Estado y es necesariamente excepcional (2007: 37).

En la actualidad, la excepcionalidad de la relación interina ha venido a modificarse en detrimento de las condiciones laborales de estos servidores, cuya condición se mantiene durante tiempo indefinido. Se considera que esta situación no puede ser explicada exclusivamente desde un ángulo estrictamente jurídico, sino que la regulación actual del empleo público debe entenderse desde el contexto de las transformaciones del Estado durante la segunda mitad del Siglo XX.

\section{LA CRISIS DE 1973 Y SUS REPERCUSIONES EN LA ORGANIZACIÓN DEL EMPLEO PÚBLICO}

Si bien, el modelo económico actual, no es un modelo que surge propiamente de la crisis de 1973, se trata de una conjunción de una serie de cambios económicos que se han venido a denominar acumulación flexible (Harvey, 2004) con las ideas de la economía clásica, que subsisten como crítica del Estado de Bienestar $y$ las ideas de la economía keynesiana.

Por acumulación flexible se entiende a un modelo que apela a la flexibilidad, con relación a los procesos laborales, los mercados de mano de obra, los productos y las pautas de consumo: se caracteriza por la emergencia de sectores totalmente nuevos de producción, nuevas formas de proporcionar servicios financieros, nuevos mercados y sobre todo, niveles intensos de innovación comercial, tecnológica y organizativa (Harvey, 2004: 170- 171).

Por su parte, a nivel político surge el pensamiento neoliberal como reacción al 
intervencionismo estatal. Dicha ideología centra su interés en el papel del mercado como modelo de regulación por lo que su preocupación política consiste en "lograr que el Mercado se encuentre efectivamente en equilibrio" (Hinkelammert, 2002: 135). Desde esta concepción, la acción estatal es vista como una distorsión al equilibrio del mercado, por lo que debe ser restringida, mediante la restricción del presupuesto, la eliminación de ayudas económicas y el control de la inflación.

Estas nuevas ideas a nivel económico, político y laboral repercuten, en diferentes niveles del Derecho, generando procesos de reforma profunda en el tamaño, funciones del Estado $y$ sus relaciones con la sociedad civil. En el campo de la organización laboral, la tendencia a la acumulación flexible se expresa en la formulación del neolaboralismo (De Buen, 2001: 135), que cuestiona a las reglas clásicas del derecho laboral, como el salario mínimo, derecho a la jornada máxima, el trabajo indefinido, entre otras; las cuales son vistas como rigideces frente al mercado $y$ el surgimiento de nuevas ideas que flexibilizan estos derechos dentro de las necesidades de la empresa privada.

Esto va a implicar la privatización, el cierre de empresas públicas y su reconversión hacia esquemas privados y en el ámbito del derecho estatutario, el cambio hacia formas de contratos a plazo fijo, venta de servicios o outsourcing y el cuestionamiento de los fundamentos tradicionales de la relación estatutaria: empleo de por vida, principio de carrera y sistema retributivo general — por categorías - a los que se imputa de causar fallas en la productividad, la motivación y la actualización profesional de los empleados públicos (Cf. en ese sentido Parejo, 2003:148).

\section{LAS REPERCUSIONES DEL MODELO NEOLIBERAL EN EL EMPLEO PÚBLICO COSTARRICENSE}

Los estudiosos del proceso neoliberal (Ffrench, 2007; Mesa, 2002) indican sin embargo, que en el caso costarricense, no es susceptible de ser reducidos al proceso de liberalización, sino que adquiere una expresión propia basada en la implementación gradual, permitiendo la reconversión productiva de la economía costarricense hacia un modelo basado en el fomento de las exportaciones y la inversión extranjera.

En Costa Rica, el pensamiento neoliberal se implementa como una respuesta a la crisis de la deuda externa durante la década de los años ochenta, a partir de una serie de nuevos cuadros intelectuales que van a cuestionar al pensamiento intervencionista determinante hasta entonces, $y$ van a promover el regreso a un modelo de fomento a las exportaciones mediante la implementación de los Programas de Ajuste Estructural. El diagnóstico de estos cuadros consiste en la reactivación del sector agrícola (orientado a la exportación), la especialización y la eliminación de barreras arancelarias (Cf. Sojo, 1984: 247).

La aplicación del giro neoliberal en la organización del empleo público costarricense implica el surgimiento de una serie de procesos, que en algunos casos se dan simultáneamente:

a) Congelamiento de plazas: durante la Administración Monge Álvarez (19821986), se recomienda la jubilación de los empleados públicos mayores de 65 años y el congelamiento de las plazas en propiedad de los funcionarios que se acogen a la jubilación (Cf. en este sentido Mesa, 2002: 473). Dichas plazas en propiedad pasan a ser ocupadas por servidores a nivel interino. Durante los gobiernos posteriores surgen nuevas formas de contrato, distintas al empleo público clásico como pago de servicios profesionales para consultorías por proyecto, contratos a plazo fijo, entre otras.

b) Movilidad laboral: dentro de la estrategia de los programas de ajuste estructural aplicados entre las administraciones Arias Sánchez y Calderón Fournier se establecen programas de movilidad laboral, en donde se eliminan como puestos del sector público, funciones o actividades no esenciales como limpieza, vigilancia, mantenimiento y transporte (Cf. Romero: 199,281). Estas funciones pasan a ser subcontratadas a prestatarios del 
sector privado bajo la forma de venta de servicios.

c) Surgimiento de nuevas funciones: si bien se deterioraron las funciones de generación de infraestructura (como la construcción de obra pública, la cual es cedida a prestatarios de tipo privado) o prestación de servicios en la salud y la banca. El retiro de estas funciones trajo como correlato la creación y fortalecimiento de las funciones de supervisión y regulación mediante el surgimiento de las superintendencias (entidades financieras, pensiones y más recientemente seguros y telecomunicaciones), o la apertura de mercados mediante la creación del Ministerio de Comercio Exterior (COMEX) o la Promotora de Comercio Exterior (PROCOMER).

d) Política salarial restrictiva: dentro de las medidas de restricción en el gasto público se propone el pago insuficiente a los servidores públicos, lo cual impide la recuperación del salario real promedio que hubo antes de la crisis. Esta política, hace atractivo el empleo público, en especial para los niveles gerenciales $y$ ejecutivos, lo cual incide en su eficiencia $y$ productividad. Para los impulsores de esta medida, menos empleados mejor pagados dan como resultado un sector público más eficiente (Lizano, s.f.: 80).

La principal consecuencia de la reforma neoliberal relacionada con el empleo es que el Estado Costarricense ha ido perdiendo su papel dinámico como impulsor de actividades y generador de empleo, el modelo de desarrollo que va tomando forma le otorga ese papel al sector privado (Castro, 2007: 133).

A nivel legal, si bien estas modalidades no implicaron reformas legales que vinieran a modificar el régimen de empleo público establecido en la Constitución Política y el Estatuto del Servicio Civil, los cambios durante el período neoliberal debilitaron la figura del empleo público, lo cual se expresa en la precarización de la estabilidad laboral de los servidores interinos, al generarse niveles de incertidumbre que estimularon la salida del personal con mayor experiencia y permitió la generalización del trabajo interino, el cual empezó a funcionar con criterios políticos y un amplio margen de discrecionalidad administrativa.

\section{EL ACTIVISMO JUDICIAL COMO FRENO A LA DISCRECIONALIDAD ADMINISTRATIVA}

Como se mencionaba anteriormente, si bien en Costa Rica, se dio una aplicación del giro neoliberal en el campo de las políticas de empleo público, estos cambios no se tradujeron en la regulación del trabajo interino, lo cual se vino a acentuar con los intentos por introducir nuevo personal interino.

Un segundo aspecto a destacar es la expansión relacionada con los derechos y con estos la creación de nuevas figuras como la Sala Constitucional o la Defensoría de los Habitantes, así como el surgimiento de nuevos derechos como los de la infancia, las mujeres, la población indígena o las personas con discapacidad.

Es en este contexto, que ante el surgimiento de nuevas realidades jurídicas, que la reciente Sala Constitucional se consolida como espacio de defensa de los derechos constitucionales. Se empieza a introducir interpretaciones mutativas (Saguës, 2006: 37), en donde mediante la interpretación judicial se introducen nuevos sentidos al texto constitucional ante vacíos de la norma ${ }^{2}$.

En materia de empleo público, se produjo un traslado a la sede judicial, donde los afectados podían resolver sus conflictos ante la instancia constitucional, como una institución que podía ofrecer soluciones desde la protección de los derechos humanos. Es en el espacio judicial donde se introduce la principal reforma judicial en materia de empleo público, mediante la creación de la doctrina de la estabilidad impropia, creada por la Sala Constitucional.

$2 \quad$ Frente a la crítica generalizada al llamado activismo judicial, es importante recordar que esta es una tendencia mundial, en la que los jueces dejan de ser vistos como meros aplicadores del derecho y se resalta su rol creativo. Véase en ese sentido Guarnieri y Pederzoli (1999), quienes analizan la "judicialización de la política" en el contexto europeo. 
Dicha doctrina señala el derecho a permanecer a menos que se nombre a un trabajador en propiedad, pero indica que la Administración no puede abusar de este carácter excepcional.

En ese sentido, indica la Sala Constitucional que:

El nombramiento de los servidores interinos por plazos que se prolongan en forma indefinida solo pueden conducir a lo que nuestros Constituyentes pretendían evitar: que existan funcionarios públicos pero sin contar con la garantía de inamovilidad que establece la Constitución [Véase en este sentido voto 867-91 de las quince horas del 3 de mayo de 1991].

La doctrina de la estabilidad impropia sin embargo, no es absoluta, sino que se encuentra sujeta a los siguientes límites: 1) Cuando se nombra a otro servidor en propiedad (plaza vacante); 2) Cuando se reincorpora el propietario a su puesto (plazo no vacante); 3) Cuando el interino inicialmente nombrado lo fue por inopia, es decir que no cumple con los requisitos de idoneidad exigidos por la ley; 4) Cuando no supera el período de prueba establecido por la ley; 5) En los casos de reestructuración o disminución de plazas (Véase en ese sentido, Sala Constitucional 2007-012545 de 10: 48 horas del 31 de agosto del 2007).

Parte de la fuerza de la doctrina judicial de la estabilidad impropia, es que dentro de la resolución de muchos de estos casos, la Sala Constitucional, establece como medida cautelar que la persona amparada permanezca en el puesto que ostentaba, mientras se resuelve, lo que permite que el afectado continué trabajando o que busque otras fuentes de empleo.

La mayoría de estos casos, que se declaraban con lugar, fueron obligando a los gobiernos de turno a respetar el derecho a la prórroga de los trabajadores interinos ante el temor de incurrir en el delito de desobediencia. Esto ha llevado a que paulatinamente, la doctrina de la estabilidad impropia se vaya generalizando como norma no escrita de aplicación obligatoria para los departamentos gubernamentales de recursos humanos.

\section{ALGUNOS RETOS PENDIENTES}

El modelo actual de selección de personal se centra exclusivamente en criterios académicos mediante el reconocimiento de títulos universitarios, con los cuales se establece el grupo profesional del oferente. Esta inclinación sin embargo subvalora otros criterios igualmente importantes en la selección y promoción del personal como la experiencia laboral, lo cual genera una desigualdad de los empleados más antiguos que tengan menor grado académico frente a otros que si bien pueden contar con mejores calificaciones académicas no tienen experiencia profesional.

Un cambio positivo en la dirección del reconocimiento de criterios extra académicos es la incorporación de nuevos criterios en la selección de personal. Así por ejemplo, mediante la Ley 8555, del 10 de octubre de 2006, se crea dentro del Estatuto del Servicio Civil, el Régimen Artístico.

Parte de las innovaciones del articulado es que permite el reconocimiento de personas que han adquirido la destreza e interpretación de obras artísticas haciéndolo de forma permanente o habitual $y$ en forma remunerada o con derecho a la retribución económica. Este enfoque desplaza a la concepción anterior, que se centra únicamente en los títulos académicos, lo cual generaba que muchos de estos profesionales fuesen clasificados como aspirantes o autorizados frente a profesionales con título universitario. Un ejemplo de esta clasificación se encuentra en los artículos 120, 123, 127 y 132 del Estatuto del Servicio Civil.

Es deseable que se dé un cambio en las políticas de empleo público, que reviertan la tendencia a la precarización, que se ha aludido a lo largo del artículo. La estabilidad del trabajador interino permite recuperar el poder de la voz (Hisrchman, citado por Sennet, 2000: 98) del trabajador con más antigüedad, en la gestión del servicio o empresa pública.

Un primer paso en esta dirección es un mayor control en la ejecución de las sentencias de la Sala Constitucional, aunque logran resolver a favor de los casos concretos. En el mismo sentido, es urgente una reforma legislativa que 
incorpore los precedentes constitucionales, porque esto no se ha traducido en una política general de respeto al trabajador interino.

\section{CONCLUSIONES}

La presente investigación pretendió mostrar las interrelaciones entre el desarrollo de las figuras jurídicas con los cambios en los modelos políticos o económicos.

En el caso del empleo público, su desarrollo o crisis depende del concepto de Estado que maneje el grupo que se encuentre en el poder. En el keynesianismo, la expansión del Estado fomentó el desarrollo de empleo público en condiciones de estabilidad social. A partir de la entrada del neoliberalismo como doctrina dominante a nivel económico y político, se aplican políticas de contención del gasto que reducen la cantidad de plazas en el sector público y que precarizan sus condiciones.

En el caso costarricense, las políticas económicas keynesianas coincidieron con una concepción de Estado que fomentó que este se convirtiera en el sector más dinámico de la economía durante las décadas del cincuenta, sesenta y setenta, lo que favoreció la expansión del trabajo en propiedad en condiciones de estabilidad a largo plazo.

Esta situación cambia con la introducción del pensamiento neoliberal que reduce las plazas en el sector público y las precariza, mediante el uso de la figura del interinazgo.

Durante este período, las principales reformas en el campo del empleo público se derivan de la jurisprudencia de la Sala Constitucional que van a introducir límites a las condiciones de estabilidad del trabajador interino. Queda pendiente una reforma que modifique a nivel legal las condiciones del empleo público y las regularice.

BIBLIOGRAFÍA

ARTÍ́CULOS DE REVISTA

Ffrench-Davis, Ricardo. "El contexto de las privatizaciones y la situación actual: entre el consenso de Washington $y$ el crecimiento con equidad". Nueva Sociedad 207. Enero-febrero, 2007.

Vargas Hidalgo, Ricardo; Vega Robert, Rolando. "La relación de empleo público y sus consecuencias prácticas en la jurisprudencia costarricense". Revista Judicial 52. Año XV. Diciembre, 1990.

DECRETOS

Servicio Civil (CR). Decreto Ejecutivo 21. Reglamento del Estatuto del Servicio Civil. Del 14 de diciembre de 1954.

JURISPRUDENCIA

Sala Constitucional (CR). Resolución 867-91 de las quince horas del 3 de mayo de 1991.

Sala Constitucional (CR). Resolución 2007012545 de 10: 48 horas del 31 de agosto de 2007.

LEYES

Servicio Civil (CR). Ley 1581. Estatuto del Servicio Civil. Del 30 de mayo de 1953.

La Gaceta (CR). Ley 8555 del 10 de octubre de 2006. La Gaceta 219. Del 15 de noviembre del 2006.

LIBROS

Bautista Vivas, Oscar. Servidor público y régimen de empleo. San José: Publicaciones Jurídico Sociales SA, 2007.

Castro Valverde, Carlos; Gutiérrez Espeleta, Lucy; Rodríguez Solera, Carlos Rafael. "Las transformaciones en la estructura social a finales del siglo $\mathrm{xx}$ (estratos sociocupacionales en el período 1987-2000)”. En: Carlos et ál. Transformaciones en la estructura social en Costa Rica. Editorial Universidad de Costa Rica, 2007.

De Buen, Néstor. La decadencia del Derecho del Trabajo. México: Editorial Porrúa, 2001. 
Guarnieri, Carlo; Pederzoli, Patrizia. Los jueces y la política. Madrid: Ediciones Taurus, 1999.

Harvey, David. La condición de la posmodernidad: investigación sobre los orígenes del cambio cultural. Primera reimpresión. Buenos Aires: Amorrortu Editores, 2004.

Hinkelammert, Franz J. Crítica de la razón utópica. Edición ampliada y revisada. Bilbao: Desclée de Brouwer, 2004.

Hines Céspedes, César. "El régimen del personal de la Administración Pública". Hines Céspedes, César; Rodríguez Hernández, Magally (compiladores). Apuntes de derecho administrativo. San José: Editorial Continental, 2008.

Lizano Fait, Eduardo. Ajuste y crecimiento en la economía de Costa Rica 1982-1994. San José: Academia de Centro América, s.f.

López Medina, Diego Eduardo. Teoría impura del derecho. La transformación de la cultura jurídica latinoamericana. Tercera reimpresión. Bogotá: Editorial Legis, 2005.

Mesa Lago, Carmelo. Buscando un modelo económico en América Latina ¿Mercado, socialista o mixto? Venezuela: Editorial Nueva Sociedad, 2002.

Parejo Alfonso, Luciano. "Crisis y renovación en el Derecho Público". Serie Cuadernos de Época. Buenos Aires: Editorial Ciudad Argentina, 2003.

Rodríguez Solera, Carlos Rafael. "Estratificación y movilidad socioocupacional en Costa Rica en la segunda mitad del siglo Xx". En: Castro Valverde, Carlos et ál. Transformaciones en la estructura social en Costa Rica. Editorial Universidad de Costa Rica, 2007.

Romero Pérez, Jorge Enrique. Derecho Administrativo General. San José: Editorial UNED, 1999.

Saguës, Néstor Pedro. La interpretación judicial de la Constitución. Segunda edición. Buenos Aires: Lexis Nexis, 2006.

Sánchez Morón, Miguel. Derecho de la función pública. Tercera Edición. Primera reimpresión. Madrid: Editorial Tecnos, 2002.

Sennet, Richard. La corrosión del carácter. Las consecuencias personales del trabajo en el nuevo capitalismo. Barcelona: Editorial Anagrama, 2000.

Sojo, Ana. Estado empresario y lucha política en Costa Rica. San José: EDUCA, 1984.

Vile, M. J. C. Constitucionalismo y separación de poderes. Madrid: Centro de Estudios Políticos y Constitucionales, 2007.

Villareal, René. La contrarrevolución monetarista. Teoría, política económica e ideología del neoliberalismo. México: Fondo de Cultura Económica, 1986.

Weber, Max. Economía y sociedad. Esbozo de sociología comprensiva. Decimotercera reimpresión. México: Fondo de Cultura Económica, 1999. 
